\title{
Physical and Electrical Analysis of Poly-Si Channel Effect on SONOS Flash Memory
}

\author{
Jun-Kyo Jeong, Jae-Young Sung, Woon-San Ko, Ki-Ryung Nam, Hi-Deok Lee and Ga-Won Lee * \\ Department of Electronics Engineering, Chungnam National University, Daejeon 305-764, Korea; \\ jjk1006@cnu.ac.kr (J.-K.J.); sjy5290@o.cnu.ac.kr (J.-Y.S.); kowoon98@cnu.ac.kr (W.-S.K.); \\ nkr0927@cnu.ac.kr (K.-R.N.); hdlee@cnu.ac.kr (H.-D.L.) \\ * Correspondence: gawon@cnu.ac.kr; Tel.: +82-42-821-5666; Fax: +82-42-823-9544
}

Citation: Jeong, J.-K.; Sung, J.-Y.; Ko, W.-S.; Nam, K.-R.; Lee, H.-D.; Lee, G.-W. Physical and Electrical Analysis of Poly-Si Channel Effect on SONOS Flash Memory. Micromachines 2021, 12, 1401. https://doi.org/10.3390/ $\operatorname{mi} 12111401$

Academic Editors: Zhongrui Wang and Jung Ho Yoon

Received: 17 September 2021 Accepted: 12 November 2021 Published: 15 November 2021

Publisher's Note: MDPI stays neutral with regard to jurisdictional claims in published maps and institutional affiliations.

Copyright: (c) 2021 by the authors. Licensee MDPI, Basel, Switzerland. This article is an open access article distributed under the terms and conditions of the Creative Commons Attribution (CC BY) license (https:/ / creativecommons.org/licenses/by/ $4.0 /)$.

\begin{abstract}
In this study, polycrystalline silicon (poly-Si) is applied to silicon-oxide-nitride-oxidesilicon (SONOS) flash memory as a channel material and the physical and electrical characteristics are analyzed. The results show that the surface roughness of silicon nitride as charge trapping layer (CTL) is enlarged with the number of interface traps and the data retention properties are deteriorated in the device with underlying poly-Si channel which can be serious problem in gate-last 3D NAND flash memory architecture. To improve the memory performance, high pressure deuterium $\left(\mathrm{D}_{2}\right)$ annealing is suggested as a low-temperature process and the program window and threshold voltage shift in data retention mode is compared before and after the $\mathrm{D}_{2}$ annealing. The suggested curing is found to be effective in improving the device reliability.
\end{abstract}

Keywords: SONOS; flash memory; poly silicon; roughness; data retention; atomic force microscope (AFM); x-ray photoelectron spectroscopy (XPS); deuterium annealing

\section{Introduction}

As the nonvolatile memory market grows rapidly, a lot of research has been reported to improve the device performance and reliability. Especially, 3D silicon-oxide-nitride-oxidesilicon (SONOS) flash memory structure has been suggested to overcome the physical limitation in scaling down the feature size of the existing 2D structure [1-5]. Representative ones are the Stacked Memory Array Transistor (SMArT) by SK Hynix, the Pipe Bit Cost Scalable (P-BiCs) by Kioxia, and Terabit Cell Array Transistor (TCAT) by Samsung. One of the distinct changes in these 3D structures is that a crystalline silicon (c-Si) channel is replaced by a polycrystalline silicon (poly-Si). Poly-Si film is composed of crystalline grains with different crystallographic orientations and grain boundaries with highly defective interfaces [6]. The random mixed structure of grains and grain boundaries is known to cause rough surface compared to a c-Si, which can deteriorate the device performances. In addition, as the area and thickness of the cell decrease due to high integration, the polysilicon channel effect may become more severe. Among the 3D SONOS structures, the devices similar to TCAT structure are based on a gate-last process. That is, a poly-Si channel is first formed and then silicon nitride $\left(\mathrm{Si}_{3} \mathrm{~N}_{4}\right)$ as a charge trapping layer (CTL) is deposited. In this case, the characteristics of the CTL will be affected with the underlayer's topology because thickness of the CTL is only a few $\mathrm{nm}$. The memory window, date retention as well as program/erase speed of SONOS devices are most affected by trap properties of CTL [7-9]. Therefore, when the underlaying poly-Si has large surface roughness as discussed above, the mismatch between materials can be intensified causing larger interface traps and a problem in the device reliability.

In this study, the physical and electrical properties of SONOS device with poly-Si channel are analyzed. Atomic force microscope (AFM) to measure the surface roughness and $x$-ray photoelectron spectroscopy (XPS) to find out the bonding energy of CTL films with poly-Si underlayer were used. For the electrical analysis, threshold voltage $\left(\mathrm{V}_{\mathrm{TH}}\right)$ shift 
was extracted through the data retention measurements. Moreover, to improve the memory properties, high pressure deuterium $\left(D_{2}\right)$ annealing is suggested. $D_{2}$ annealing has recently emerged to improve the reliability of MOSFET device by curing shallow traps $[10,11]$. The experimental results show that by $\mathrm{D}_{2}$ annealing the reliability of the SONOS device with poly-Si channel can be improved at low temperature.

\section{Experiments}

A SONOS structured capacitors were fabricated with c-Si and poly-Si as channels. Figure 1 shows the cross-sectional view and process flow of the device. Prime grade $\mathrm{p}$-type $\mathrm{c}-\mathrm{Si}$ was used as the substrate, and the thickness of tunneling oxide $\left(\mathrm{TO}, \mathrm{SiO}_{2}\right), \mathrm{CTL}\left(\mathrm{Si}_{3} \mathrm{~N}_{4}\right)$, and blocking oxide $\left(\mathrm{BO}, \mathrm{SiO}_{2}\right)$ was $7 \mathrm{~nm}, 15 \mathrm{~nm}$ and $15 \mathrm{~nm}$, respectively. In the case of a poly-Si channel device, $200 \mathrm{~nm}$ of thermal $\mathrm{SiO}_{2}$ was grown to isolate c-Si and poly-Si, and $50 \mathrm{~nm}$ of poly-Si was deposited by low pressure chemical vapor deposition (LPCVD). For $\mathrm{TO}, \mathrm{c}-\mathrm{Si}$ channel device was grown using thermal oxidation and poly-Si channel device was deposited using LPCVD. Then, CTL and BO were deposited using LPCVD. For gate electrode, a $100 \mathrm{~nm}$ thick titanium (Ti) film was deposited by RF sputter. Table 1 shows the process conditions of $\mathrm{SiO}_{2}$ and $\mathrm{Si}_{3} \mathrm{~N}_{4}$ deposited by LPCVD. In this study, high pressure $\mathrm{D}_{2}$ annealing is suggested as a passivation method of $\mathrm{Si}_{3} \mathrm{~N}_{4}$. High pressure annealing has the advantage of reducing both processing temperature and time. After the gate formation, the annealing was performed at $450{ }^{\circ} \mathrm{C}, 10 \mathrm{~atm}, 1 \mathrm{~h}$. The fabricated devices have a gate width by length of $100 \mu \mathrm{m} / 100 \mu \mathrm{m}$.

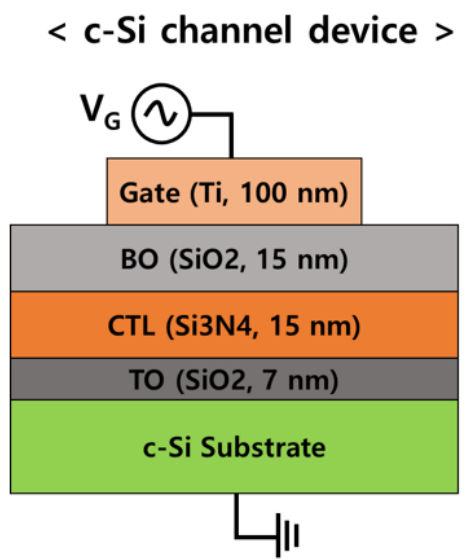

< poly-Si channel device >

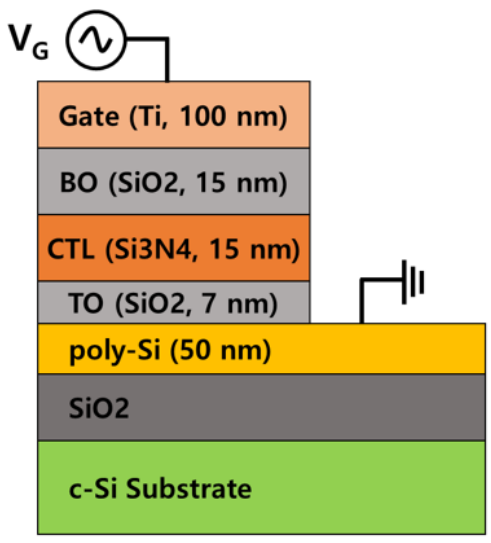

(a)

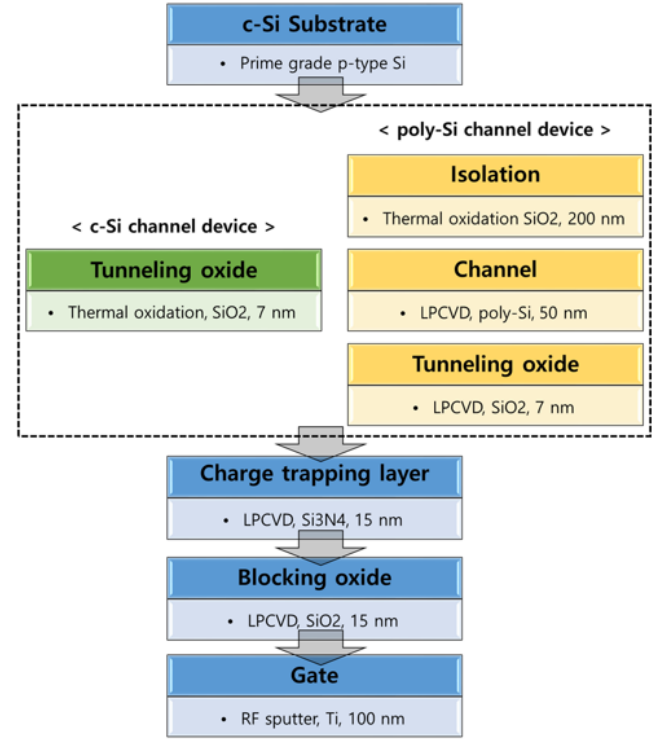

(b)

Figure 1. (a) The structures of a c-Si and poly-Si SONOS type capacitor devices, and (b) the process flow of the device fabrication.

Table 1. Process conditions of $\mathrm{SiO}_{2}\left(\mathrm{BO}\right.$ or TO) and $\mathrm{Si}_{3} \mathrm{~N}_{4}$ (CTL) deposited by LPCVD.

\begin{tabular}{cccc}
\hline LPCVD & Temperature $\left({ }^{\circ} \mathbf{C}\right)$ & Pressure (mTorr) & Composition Ratio \\
\hline $\mathrm{SiO}_{2}$ & 800 & - & $\mathrm{Si}_{(}\left(\mathrm{OC}_{2} \mathrm{H}_{5}\right)_{4}$ \\
$\mathrm{Si}_{3} \mathrm{~N}_{4}$ & 720 & 200 & $\mathrm{SiH}_{2} \mathrm{Cl}_{2}: \mathrm{NH}_{3}=20: 120$ \\
\hline
\end{tabular}

\section{Results and Discussion}

\subsection{Physical Characteristic Analysis}

AFM was used to compare the surface roughness of nitride-oxide (NO) stacked film on c-Si and poly-Si. Figure 2a,b shows the AFM images of NO on c-Si, poly-Si. As a 
reference, the surface roughness of poly-Si on Si substrate is presented in Figure 2c. From Figure $2 \mathrm{a}, \mathrm{b}$, it can be seen that $\mathrm{Si}_{3} \mathrm{~N}_{4}$ has very rough surface on poly-Si. In Table 2, the extracted roughness values are summarized. From the results, it can be seen that the surface roughness of a film is affected by the underlayer.

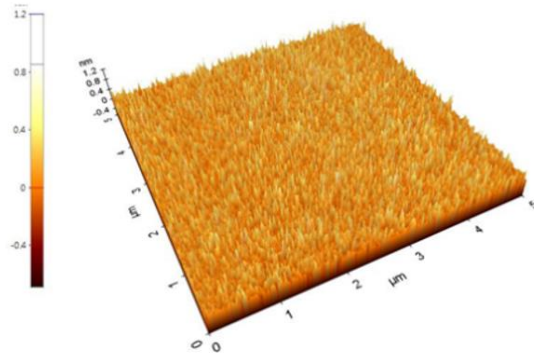

(a)

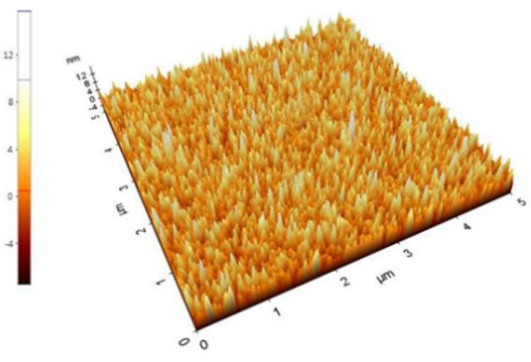

(b)

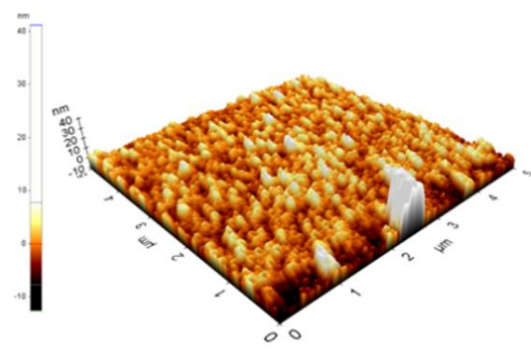

(c)

Figure 2. AFM images of fabricated devices in a square region about $5 \mu \mathrm{m} / 5 \mu \mathrm{m}$. The device structures are (a) NO on c-Si, (b) NO on poly-Si, and (c) only poly-Si deposited on Si substrate, respectively.

Table 2. AFM analysis results on surface roughness of NO stacked film on c-Si and poly-Si. In addition, poly-Si roughness is also measured for a reference which is expressed as "Only polySi" sample.

\begin{tabular}{cccc}
\hline Condition & Peak to Valley $(\mathbf{n m})$ & Mean Height $(\mathbf{n m})$ & RMS Roughness $(\mathbf{n m})$ \\
\hline c-Si channel & 1.2 & 0 & 0.157 \\
Poly-Si channel & 15.715 & 0.494 & 2.422 \\
Only poly-Si & 12.627 & 0.158 & 2.660 \\
\hline
\end{tabular}

From the AFM results, the cross section of the poly-Si device can be drawn as Figure 3, where the roughness of poly-Si causes poor coverage of TO and CTL resulting in the thickness and electric filed fluctuation in each layer. In this case, the electrical characteristics of device are deteriorated by the local increase of electric field in the thin area [12,13]. In addition, the interface roughness influences the interface defect formation by intensifying the lattice constant mismatch between the layers [14,15]. It is well known that the shallow interface traps between TO and CTL affects SONOS flash memory performance [16,17].

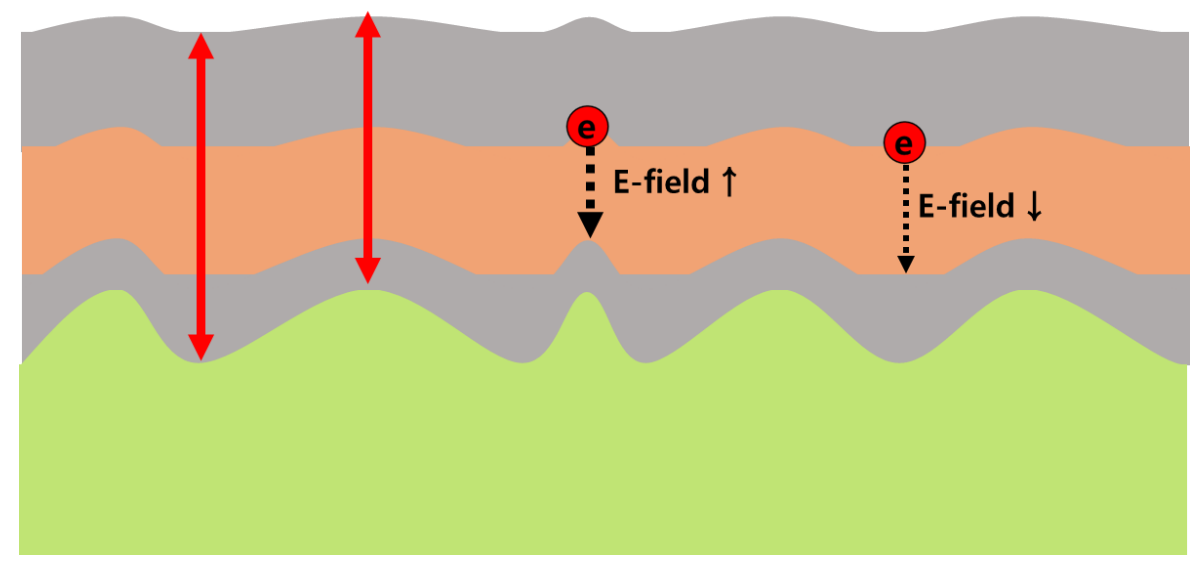

Figure 3. Schematic cross section of a SONOS transistors with poly-Si channel. The roughness of poly-Si causes poor coverage of tunneling oxide and nitride resulting in large electric field fluctuation in each layer. 


\section{XPS Analysis}

The depth profile analysis of XPS was performed to investigate the bonding structure of the TO and CTL interface according to the channel material change. Figure 4 shows the XPS multi-peak fitting results of Si 2p peak, which are corrected to $285.5 \mathrm{eV}$ of C 1s. The Si $2 p$ spectra can be fitted by 4 peaks using a Gaussian function. Si-Si peak is $99.9 \pm 0.15 \mathrm{eV}, \mathrm{Si}_{-} \mathrm{Si}_{\mathrm{x}} \mathrm{N}_{\mathrm{y}}$ peak is $101.3 \pm 0.15 \mathrm{eV}, \mathrm{Si}_{3} \mathrm{~N}_{4}$ peak is $102.1 \pm 0.1 \mathrm{eV}$, and $\mathrm{SiO}_{2}$ peak is $103.4 \pm 0.1 \mathrm{eV}[18,19]$. $\mathrm{Si}_{-} \mathrm{Si}_{\mathrm{x}} \mathrm{N}_{\mathrm{y}}$ bonding represents a combination of $\mathrm{Si}_{3} \mathrm{~N}_{4}$ that does not match the composition ratio. Table 3 shows the peak positions and ratios in each device. Ratio is the percentage of the area of each peak to the total area of the peak. The Si-Si and $\mathrm{SiO}_{2}$ ratios show similar percentages, but the $\mathrm{SixNy}$ and $\mathrm{Si}_{3} \mathrm{~N}_{4}$ ratios show opposite results. The reason why the Si-SixNy bonding ratio is higher in poly-Si devices can be explained by the interface degradation as in AFM analysis. $\mathrm{Si}_{-}-\mathrm{Si}_{\mathrm{x}} \mathrm{N}_{\mathrm{y}}$ bonding acts as trap in the CTL and affects the reliability of the memory.

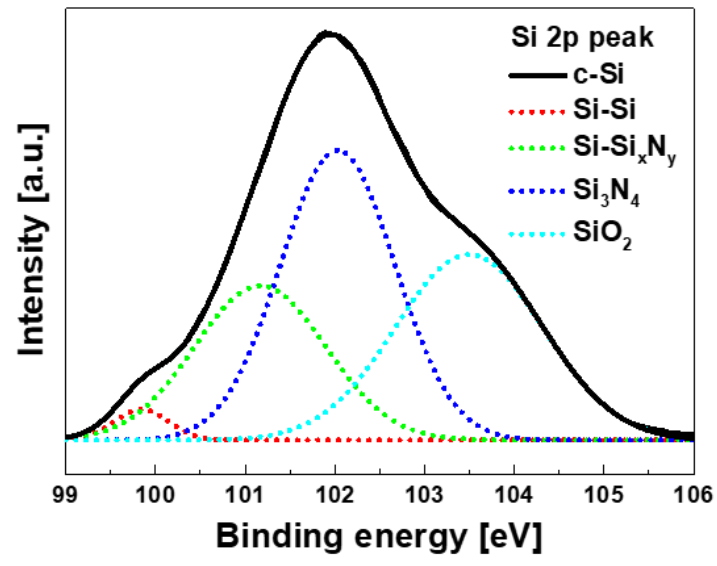

(a)

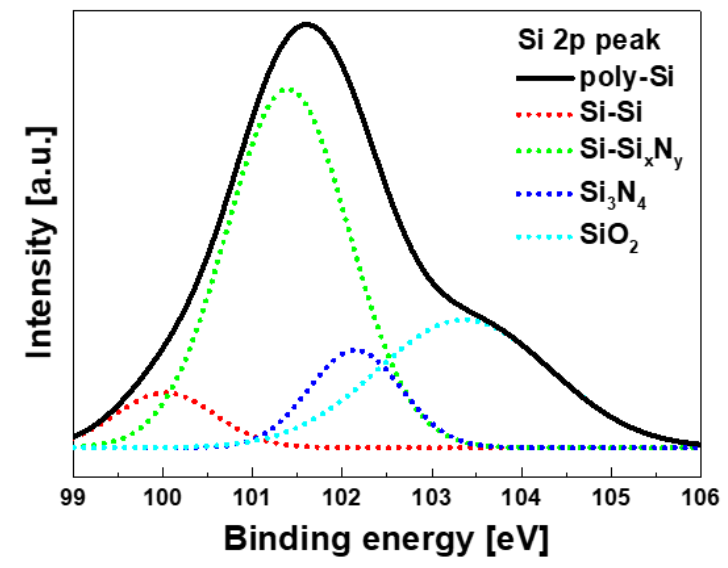

(b)

Figure 4. X-ray Photoelectron Spectroscopy (XPS) results of Si 2p multi peak fitting of tunneling oxide/charge trapping layer interface on (a) c-Si and (b) poly-Si channel device.

Table 3. Extraction results of Si 2p peak parameters according to underlaying channel material.

\begin{tabular}{cccccccccc}
\hline c-Si & $\mathbf{S i}-\mathbf{S i}$ & $\mathbf{S i}_{\mathbf{x}} \mathbf{N}_{\mathbf{y}}$ & $\mathbf{S i}_{\mathbf{3}} \mathbf{N}_{\mathbf{4}}$ & $\mathbf{S i O}_{\mathbf{2}}$ & poly-Si & $\mathbf{S i}-\mathbf{S i}$ & $\mathbf{S i}_{\mathbf{x}} \mathbf{N}_{\mathbf{y}}$ & $\mathbf{S i}_{\mathbf{3}} \mathbf{N}_{\mathbf{4}}$ & $\mathbf{S i O}_{\mathbf{2}}$ \\
\hline Peak $(\mathrm{eV})$ & 99.84 & 101.17 & 102.03 & 103.49 & Peak (eV) & 100.02 & 101.39 & 102.14 & 103.36 \\
Ratio $(\%)$ & 2 & 25 & 40 & 33 & Ratio (\%) & 7 & 54 & 11 & 28 \\
\hline
\end{tabular}

Figure 5 shows the basic structure of $\mathrm{Si}_{3} \mathrm{~N}_{4}$ and the trap model. In $\mathrm{Si}_{3} \mathrm{~N}_{4}$, silicon vacancy $\left(\mathrm{V}_{\mathrm{Si}}\right)$ and nitrogen vacancy $\left(\mathrm{V}_{\mathrm{N}}\right)$ can be made, and their properties can be changed by atoms entering the vacancy. In general, interface traps have relatively shallower energy traps than bulk traps. As a characteristic of the SONOS structure, since the CTL is adjacent to the oxide layer, oxygen related defects may be formed by oxygen diffusion in the TO or BO. In particular, the bond by the $\mathrm{O}$ atom substituted with $\mathrm{V}_{\mathrm{N}}$ has a small energy level [20]. From the physical analysis, it was confirmed that the roughness deterioration of the underlayer formed more $\mathrm{V}_{\mathrm{Si}}$ and $\mathrm{V}_{\mathrm{N}}$ between the TO/BO and CTL, and the increase of the interface trap had a significant effect on the reliability of the memory [20-22]. 


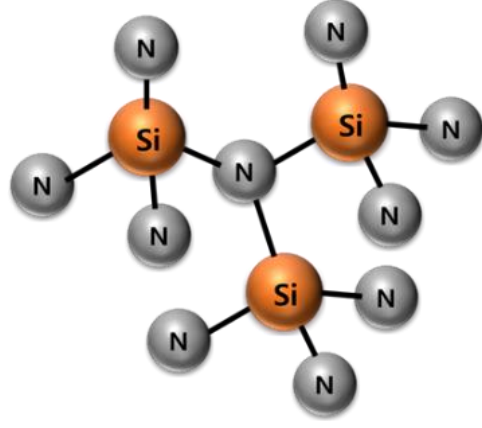

<Stoichiometric Silicon Nitride>

(a)

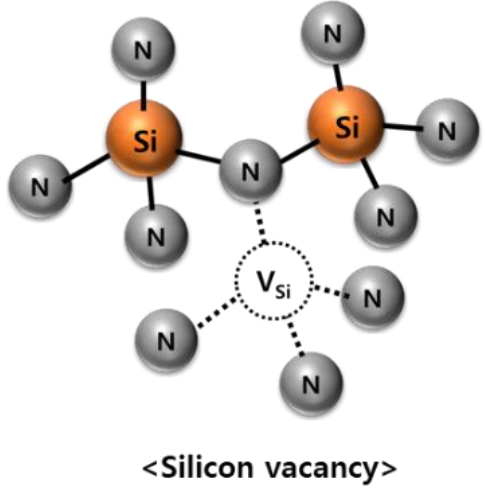

(b)

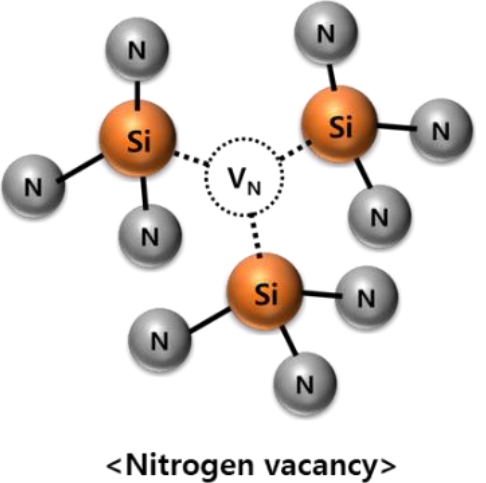

(c)

Figure 5. (a) Standard structure of the crystal $\mathrm{Si}_{3} \mathrm{~N}_{4}$. Main defects (b) silicon vacancy and (c) nitrogen vacancy.

\subsection{Electrical Characteristic Analysis}

\subsubsection{Data Retention Measurement}

The program (PRG) and data retention behavior of the fabricated devices were measured as shown in Figure 6 and the charge loss in data retention mode was calculated. In data retention mode, $\mathrm{C}-\mathrm{V}$ were measured after baking at $75 \sim 125^{\circ} \mathrm{C}\left(25^{\circ} \mathrm{C}\right.$ step) for $1 \mathrm{~h}$ after programming. Poly-Si channel shows large program window (higher $\mathrm{V}_{\mathrm{TH}}$ shift) at the same program voltage than c-Si channel. However, larger $\mathrm{V}_{\mathrm{TH}}$ shift $\left(\Delta \mathrm{V}_{\mathrm{TH}}\right)$ in the data retention meaning inferior reliability. Figure 7 shows $\Delta \mathrm{V}_{\mathrm{TH}}$ in the data retention mode according to temperature. $\mathrm{V}_{\mathrm{TH}}$ was extracted as a gate voltage at $80 \%$ of the maximum capacitance. $\Delta \mathrm{V}_{\mathrm{TH}}$ is much larger in all temperature conditions and the data retention characteristics are deteriorated in poly-Si devices. Considering shallow traps improves program windows with the traditional tradeoff in data retention properties, the experimental results show that more traps exist in the poly-Si channel device, which is same with the previous physical analysis.

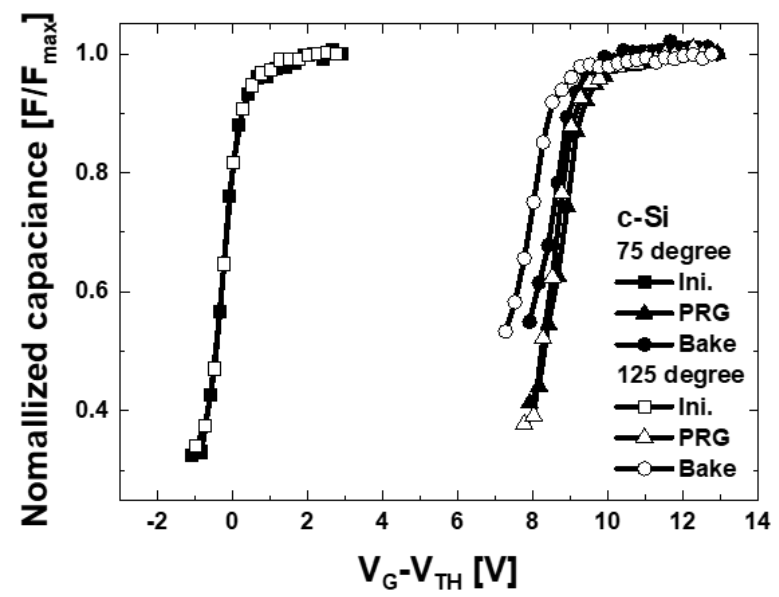

(a)

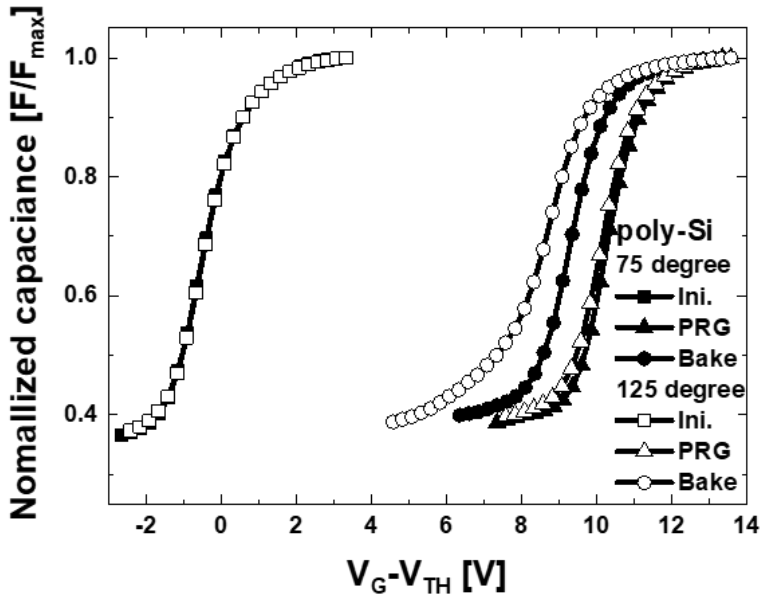

(b)

Figure 6. Measurement result of program and data retention characteristics of the fabricated devices. Here, the retention properties were measured after baking at $75 \sim 125{ }^{\circ} \mathrm{C}$ for $1 \mathrm{~h}$. 


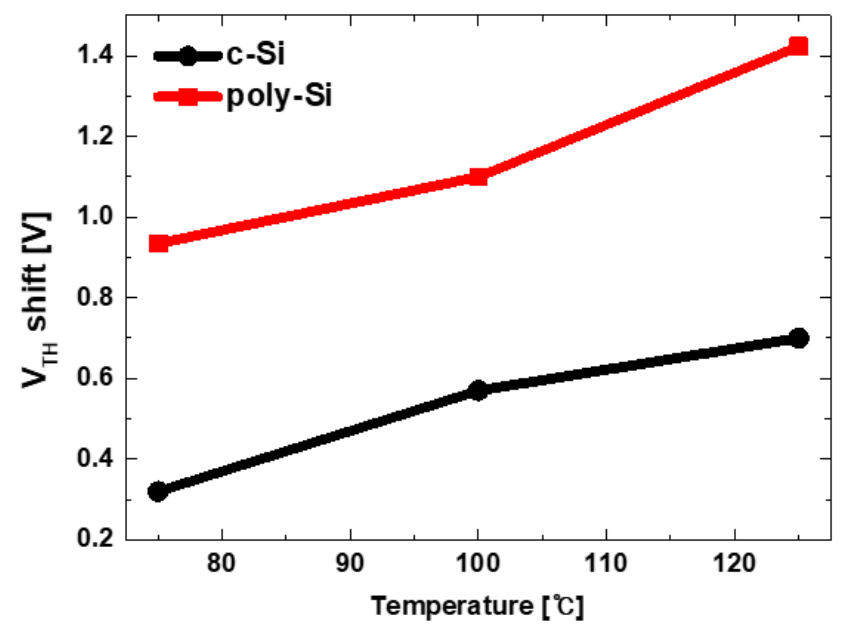

Figure 7. $\Delta \mathrm{V}_{\mathrm{TH}}$ of c-Si and poly-Si channel devices in data retention mode according to the temperature.

\subsubsection{High Pressure $\mathrm{D}_{2}$ Annealing Effect}

In this study, high pressure $\mathrm{D}_{2}$ annealing is suggested to make the device stable as a low temperature process method. Figure 8 shows trap models in $\mathrm{Si}_{3} \mathrm{~N}_{4}$. Figure 8a shows $4 \mathrm{~N}-\mathrm{H}$ defect where hydrogen enters into $\mathrm{V}_{\mathrm{Si}}$. This defect can be ignored because its energy level is not in the bandgap [23]. In Figure $8 b$, hydrogen enters into nitrogen vacancy $\left(\mathrm{V}_{\mathrm{N}}\right)$ and forms a $1 \mathrm{Si}-\mathrm{H}$ defect and some Si-Si bonds [24,25]. Figure 8c shows O-related traps due to oxygen diffusion into $V_{N}$ [26], which is common near oxide film similar to TO/CTL or CTL/BO interface. In this experiment, to suppress O-related defects near TO/CTL or $\mathrm{CTL} / \mathrm{BO}$ interface, passivation of $\mathrm{V}_{\mathrm{N}}$ is focused and high pressure $\mathrm{D}_{2}$ annealing is applied as stable curing method at low temperature.

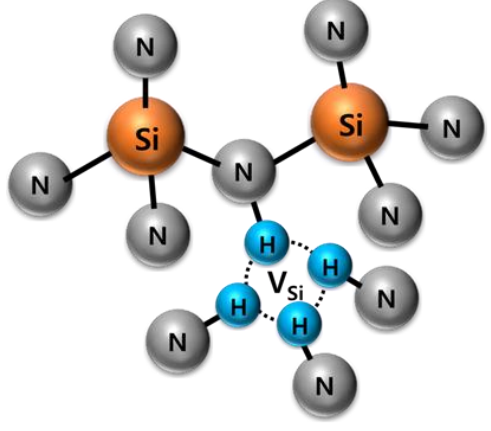

$<\mathrm{V}_{\mathrm{Si}}, 4 \mathrm{~N}-\mathrm{H}$ defect $>$

(a)

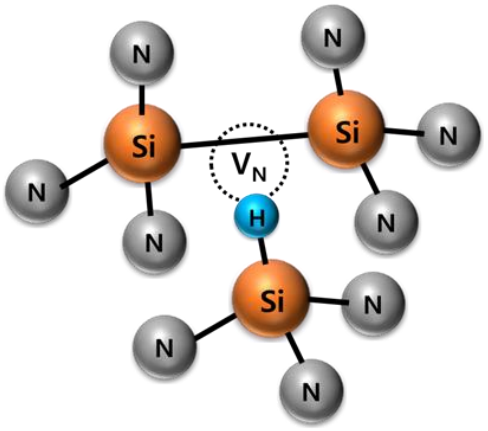

$<\mathrm{V}_{\mathrm{N}}, 1 \mathrm{Si}-\mathrm{H}$ defect $>$

(b)

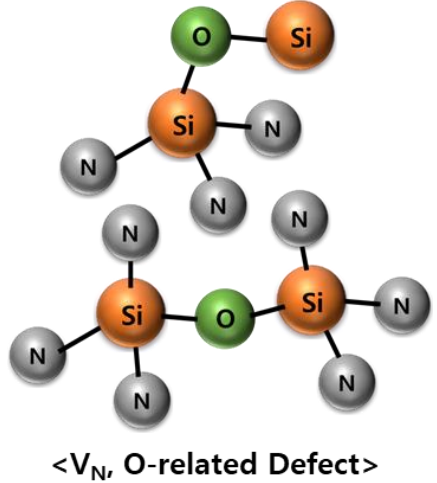

(c)

Figure 8. Trap model that can appear in the TO/CTL interface after high pressure $\mathrm{D}_{2}$ annealing. (a) $\mathrm{V}_{\mathrm{Si}}$ with substitutional $\mathrm{H}$ atom at $\mathrm{Si}$ site, (b) $\mathrm{V}_{\mathrm{N}}$ with substitutional $\mathrm{H}$ atom at $\mathrm{N}$ site or Si-Si bond form, and (c) $\mathrm{V}_{\mathrm{N}}$ with substitutional $\mathrm{O}$ atom at $\mathrm{N}$ site.

Figure 9 shows the $\mathrm{C}-\mathrm{V}$ data retention measurement results according to high pressure $\mathrm{D}_{2}$ annealing of a poly-Si channel device. Table 4 shows the $\mathrm{V}_{\mathrm{TH}}$ extracted according to the measurement temperature and high pressure $\mathrm{D}_{2}$ annealing. After $\mathrm{D}_{2}$ passivation through high pressure annealing, the memory window decreased, but the device reliability was greatly improved. These results are consistent with the previously predicted effect of shallow trap curing of $\mathrm{Si}_{3} \mathrm{~N}_{4}$ by $\mathrm{D}_{2}$ annealing [27]. This result implies that even though the hydrogen can be dissociated during the post annealing period, some could form stable bondage with $\mathrm{Si}$ and $\mathrm{N}$ atoms. Furthermore, previous research had conducted $\mathrm{D}_{2}$ high pressure annealing even at $900{ }^{\circ} \mathrm{C}$ temperature [28]. 
For the physical analysis on the reduced shallow trap density, it is needed to detect the change in atomic bonding in $\mathrm{Si}_{3} \mathrm{~N}_{4}$ by the deuterium bonding. FT-IR analysis can be employed for detecting and determining bond densities of light atoms such as $\mathrm{H}_{2}$ or $\mathrm{D}_{2}$ [29]. In this experiment, the results are not presented but Thermo-Nicolet 5700 FT-IR spectrometer is analyzed on the c-Si channel device with and without $\mathrm{D}_{2}$ treatment where the sample with $\mathrm{D}_{2} \mathrm{HPA}$ with $600{ }^{\circ} \mathrm{C}$ annealing shows slightly increased absorbance in the rage of $2375 \mathrm{~cm}^{-1}$. It is difficult to detect the light atoms such as hydron quantitatively, more precise physical method should be studied.

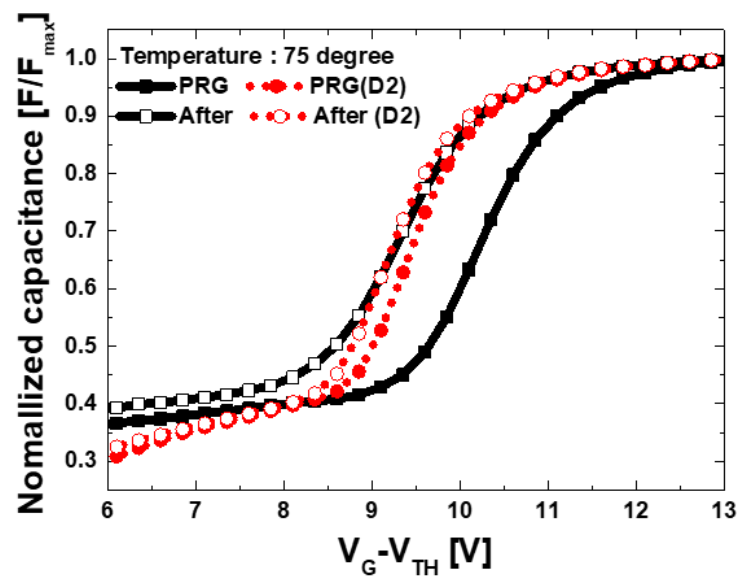

(a)

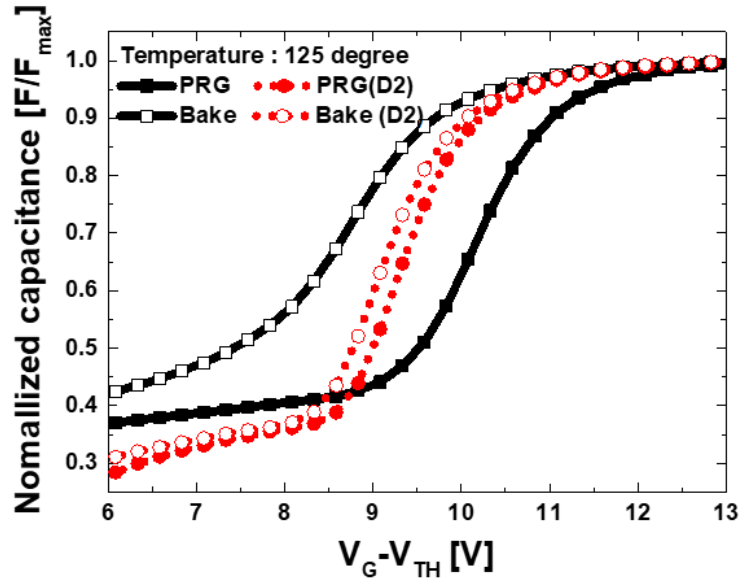

(b)

Figure 9. The result of measuring the program and data retention characteristics of the manufactured device according to the high pressure $\mathrm{D}_{2}$ annealing of the poly-Si channel device. Data retention measurement temperature (a) $75^{\circ} \mathrm{C}$ and (b) $125^{\circ} \mathrm{C}$.

Table 4. Extracted $\mathrm{V}_{\mathrm{TH}}$ based on data retention measurement according to temperature and high pressure $\mathrm{D}_{2}$ annealing.

\begin{tabular}{ccccc}
\hline $\begin{array}{c}\text { Temperature }\left({ }^{\circ} \mathrm{C}\right) \\
\text { Condition }\end{array}$ & No Treatment & $\mathbf{D}_{\mathbf{2}}$ Annealing & No Treatment & $\mathbf{D}_{\mathbf{2}}$ Annealing \\
\hline Program $(\mathrm{V})$ & 10.75 & 9.86 & 10.58 & 9.74 \\
Bake $(\mathrm{V})$ & 9.82 & 9.68 & 9.16 & 9.54 \\
$\Delta \mathrm{V}_{\mathrm{TH}}(\mathrm{V})$ & 0.93 & 0.18 & 1.42 & 0.20 \\
\hline
\end{tabular}

\section{Conclusions}

In this study, the physical and electrical characteristics of the SONOS flash memory device with poly-Si channel were analyzed, and high pressure $\mathrm{D}_{2}$ annealing was suggested to improve the device performance. For physical analysis, surface roughness through AFM and trap of TO/CTL interface through XPS were analyzed. From the physical analysis, it was confirmed that underlaying poly-Si deteriorates the surface roughness of CTL and enlarges physical defects. For electrical analysis, $\Delta \mathrm{V}_{\mathrm{TH}}$ was measured in data retention mode and larger in poly-Si devices as confirmed in the physical analysis. However, by high-pressure $\mathrm{D}_{2}$ annealing, the deteriorated memory characteristics can be improved. From the data retention measurement before and after $\mathrm{D}_{2}$ annealing, it was confirmed that the memory window slightly decreased due to the curing of the interface trap, but the $\Delta \mathrm{V}_{\mathrm{TH}}$ significantly decreased. The results show a problem that appears when poly-Si channel is used in SONOS devices and indicate that high pressure $\mathrm{D}_{2}$ annealing is effective method to control the trap sites in interface of CTL.

Author Contributions: Methodology, formal analysis, investigation, writing —original draft, J.-K.J.; data curation, visualization, J.-Y.S., W.-S.K. and K.-R.N.; funding acquisition, resources, H.-D.L.; conceptualization, methodology, writing-review and editing, funding acquisition, supervision, G.-W.L. All authors have read and agreed to the published version of the manuscript. 
Funding: This work was supported by the National Research Foundation of Korea (NRF) grant funded by the Korea government (MSIT) (NRF-2019M3F3A1A01074449, NRF-2019R1A2C1084717).

Data Availability Statement: Not applicable.

Conflicts of Interest: The authors declare no conflict of interest.

\section{References}

1. Yang, S.D.; Oh, J.S.; Yun, H.J.; Jeong, K.S.; Kim, Y.M.; Lee, S.Y.; Lee, H.-D.; Lee, G.-W. The short channel effect immunity of silicon nanowire SONOS flash memory using TCAD simulation. Trans. Electr. Electron. Mater. 2013, 14, 139-142. [CrossRef]

2. Xie, Q.; Lee, C.J.; Xu, J.; Wann, C.; Sun, J.Y.C.; Taur, Y. Comprehensive analysis of short-channel effects in ultrathin SOI MOSFETs. IEEE Trans. Electron. Devices 2013, 60, 1814-1819. [CrossRef]

3. Bohara, P.; Vishvakarma, S.K. NAND flash memory device with ground plane in buried oxide for reduced short channel effects and improved data retention. J. Comput. Electron. 2019, 18, 500-508. [CrossRef]

4. Endoh, T.; Kinoshita, K.; Tanigami, T.; Wada, Y.; Sato, K.; Yamada, K.; Yokoyama, T.; Takeuchi, N.; Tanaka, K.; Awaya, N.; et al. Novel ultrahigh-density flash memory with a stacked-surrounding gate transistor (S-SGT) structured cell. IEEE Trans. Electron. Devices 2003, 50, 945-951. [CrossRef]

5. Kim, H.; Ahn, S.J.; Shin, Y.G.; Lee, K.; Jung, E. Evolution of NAND flash memory: From 2D to 3D as a storage market leader. In Proceedings of the 2017 IEEE International Memory Workshop (IMW), Monterey, CA, USA, 14-17 May 2017; IEEE: Monterey, CA, USA, 2017; pp. 1-4.

6. Seager, C.H. Grain boundaries in polycrystalline silicon. Ann. Rev. Mater. Sci. 1985, 15, 271-302. [CrossRef]

7. Yamashita, Y.; Asano, A.; Nishioka, Y.; Kobayashi, H. Dependence of interface states in the Si band gap on oxide atomic density and interfacial roughness. Phys. Rev. B 1999, 59, 15872. [CrossRef]

8. Hong, S.B.; Park, J.H.; Lee, T.H.; Lim, J.H.; Shin, C.; Park, Y.W.; Kim, T.G. Variation of poly-Si grain structures under thermal annealing and its effect on the performance of TiN/Al2O3/Si3N4/SiO2/poly-Si capacitors. Appl. Surf. Sci. 2019, 477, 104-110. [CrossRef]

9. Aozasa, H.; Fujiwara, I.; Nomoto, K.; Komatsu, H.; Koyama, K.; Kobayashi, T.; Oda, T. Effects of nitridation on the electrical properties of MONOS nonvolatile memories. J. Electrochem. Soc. 2007, 154, H798. [CrossRef]

10. Kizilyalli, I.C.; Lyding, J.W.; Hess, K. Deuterium post-metal annealing of MOSFET's for improved hot carrier reliability. IEEE Electron. Device Lett. 1997, 18, 81-83. [CrossRef]

11. Cheng, K.; Hess, K.; Lyding, J.W. A new technique to quantify deuterium passivation of interface traps in MOS devices. IEEE Electron. Device Lett. 2001, 22, 203-205. [CrossRef]

12. Yang, Y.L.; Purwar, A.; White, M.H. Reliability considerations in scaled SONOS nonvolatile memory devices. Solid State Electron. 1999, 43, 2025-2032. [CrossRef]

13. Li, W.; Li, D.Y. On the correlation between surface roughness and work function in copper. J. Chem. Phys. 2005, 122, 064708. [CrossRef] [PubMed]

14. Choi, Y.W.; Xie, K.; Kim, H.M.; Wie, C.R. Interface trap and interface depletion in lattice-mismatched GaInAs/GaAs heterostructures. J. Electron. Mater. 1991, 20, 545-551. [CrossRef]

15. Huang, Z.C.; Wie, C.R.; Johnstone, D.K.; Stutz, C.E.; Evans, K.R. Effects of lattice mismatch and thermal annealing on deep traps and interface states in Ga0. 92In0. 08As (n+)/GaAs (p) heterojunctions. J. Appl. Phys. 1993, 73, 4362-4366. [CrossRef]

16. Lee, J.D.; Choi, J.H.; Park, D.; Kim, K. Effects of interface trap generation and annihilation on the data retention characteristics of flash memory cells. IEEE Trans. Device Mater. Reliab. 2004, 4, 110-117. [CrossRef]

17. Yang, S.D.; Jung, J.K.; Lim, J.G.; Park, S.G.; Lee, H.D.; Lee, G.W. Investigation of Intra-Nitride Charge Migration Suppression in SONOS Flash Memory. Micromachines 2019, 10, 356. [CrossRef] [PubMed]

18. Park, Y.B.; Rhee, S.W. Bulk and interface properties of low-temperature silicon nitride films deposited by remote plasma enhanced chemical vapor deposition. J. Mater. Sci. Mater. Electron. 2001, 12, 515-522. [CrossRef]

19. Huang, J.J.; Liu, C.J.; Lin, H.C.; Tsai, C.J.; Chen, Y.P.; Hu, G.R.; Lee, C.C. Influences of low temperature silicon nitride films on the electrical performances of hydrogenated amorphous silicon thin film transistors. J. Phys. D Appl. Phys. 2008, 41, 245502. [CrossRef]

20. Wong, H.; Gritsenko, V.A. Defects in silicon oxynitride gate dielectric films. Microelectron. Reliab. 2002, 42, 597-605. [CrossRef]

21. Lusky, E.; Shacham-Diamand, Y.; Shappir, A.; Bloom, I.; Eitan, B. Traps spectroscopy of the $\mathrm{Si}_{3} \mathrm{Ni}_{4}$ layer using localized charge-trapping nonvolatile memory device. Appl. Phys. Lett. 2004, 85, 669-671. [CrossRef]

22. Perera, R.; Ikeda, A.; Hattori, R.; Kuroki, Y. Effects of post annealing on removal of defect states in silicon oxynitride films grown by oxidation of silicon substrates nitrided in inductively coupled nitrogen plasma. Thin Solid Film 2003, 423, 212-217. [CrossRef]

23. Vianello, E.; Driussi, F.; Blaise, P.; Palestri, P.; Esseni, D.; Perniola, L.; Molas, G.; De Salvo, B.; Selmi, L. Explanation of the charge trapping properties of silicon nitride storage layers for NVMs-Part II: Atomistic and electrical modeling. IEEE Trans. Electron. Devices 2011, 58, 2490-2499. [CrossRef]

24. Gritsenko, V.A.; Perevalov, T.V.; Orlov, O.M.; Krasnikov, G.Y. Nature of traps responsible for the memory effect in silicon nitride. Appl. Phys. Lett. 2016, 109, 062904. [CrossRef] 
25. Sonoda, K.I.; Tsukuda, E.; Tanizawa, M.; Yamaguchi, Y. Electron trap level of hydrogen incorporated nitrogen vacancies in silicon nitride. J. Appl. Phys. 2015, 117, 104501. [CrossRef]

26. Yamaguchi, K.; Otake, A.; Kobayashi, K.; Shiraishi, K. Atomistic guiding principles for MONOS-type memories with high program/erase cycle endurance. In Proceedings of the 2009 IEEE International Electron Devices Meeting (IEDM), Baltimore, MD, USA, 7-9 December 2009; IEEE: Baltimore, MD, USA, 2009; pp. 1-4.

27. Noguchi, M.; Isogai, T.; Yamashita, H.; Sawa, K.; Fujitsuka, R.; Yamanaka, T.; Okada, S.; Aoyama, T.; Aiso, F.; Abe, J.; et al. Formation of High Reliability Hydrogen-free MONOS Cells Using Deuterated Ammonia. In Proceedings of the 2019 IEEE International Electron Devices Meeting (IEDM), San Francisco, CA, USA, 7-11 December 2019; IEEE: San Francisco, CA, USA, 2019; pp. 30-32.

28. Tanaka, M.; Saida, S.; Mitani, Y.; Mizushima, I.; Tsunashima, Y. Highly reliable MONOS Devices with optimized silicon nitride film having deuterium terminated charge traps. In Proceedings of the 2002 Digest. International Electron Devices Meeting, Washington, DC, USA, 2-5 December 2001; IEEE: San Francisco, CA, USA, 2003; pp. 237-240.

29. Choi, S.; Baek, S.; Jang, M.; Jeon, S.; Kim, J.; Kim, C.; Hwang, H. Effects of High-Pressure Deuterium annealing on nonvolatile memory device with silicon nanocrystals embedded in silicon nitride. J. Electrochem. Soc. 2005, 152, G345. [CrossRef] 